\title{
COMENTÁRIOS SOBRE A INTERPRETAÇÃO GUEROULTIANA DE RENÉ DESCARTES: CONTRIBUIÇÕES E CONTROVÉRSIAS
}

\author{
Commentaries on the Gueroultian interpretation of René Descartes: contributions \\ and controversies
}

Edgard Vinicius Cacho Zanette *

Resumo: No que concerne à obra de René Descartes nos remetemos prontamente à uma tradição complexa de estudos que é comumente intitulada «estudos cartesianos». Considerando a historiografia filosófica, o historiador da filosofia Martial Gueroult (1891-1976) é certamente um nome eminente. Entre diferentes obras, seus dois robustos volumes de Descartes selon $l^{\prime}$ ordre des raisons ocupam um lugar tão importante que é difícil aparecer um bom estudo de Descartes que não trate estes textos. A contraposição entre a fidelidade histórica e a compreensão estrutural da obra cartesiana é uma questão importante, a qual remete a interpretar uma filosofia de forma fidedigna, evitando anacronismos filosóficos. Neste sentido, este artigo examina elementos pertinentes sobre a interpretação de Gueroult, ao mesmo tempo em que são pontuadas suas contribuições e discutidas algumas controvérsias que colocariam em xeque esta clássica interpretação. Palavras-chave: Descartes. Cogito. Metafísica. Gueroult. História da Filosofia.

Abstract: The study of Descartes immediately leads us to the complex tradition of studies commonly entitled "Cartesian studies". In terms of philosophical historiography, the philosophy historian Martial Gueroult (1891-1976) is undoubtedly

\footnotetext{
* Doutor em Filosofia pela Unicamp. Pós-doutorado pela Universidade Federal de Uberlândia (2017). Professor da Universidade Estadual de Roraima, Boa Vista. Artigo recebido em 15/10/2015 e aprovado para publicação em 14/07/2016.
} 
a distinguished name. Among his varied publications, two solid volumes of his Descartes selon l'ordre des raisons occupy such an important place that one studying Descartes could hardly omit to mention them. The contrast between the historical fidelity and the structural understanding of Cartesian work is an important issue that demands a trustworthy interpretation of philosophy as well as the avoidance of philosophical anachronisms. The present article examines elements that are relevant to Gueroult's interpretation, while punctuating his contributions and discussing some controversies under discussion that would put in check this classic interpretation.

KEYWORDS: Descartes. Cogito. Metaphysics. Gueroult. History of Philosophy.

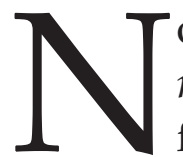

otemos que no prefácio do volume I do Descartes selon l' ordre des raisons, Gueroult inicia por promover uma distinção historiográfica fundamental, entre subordinação compreensiva de uma obra em relação à explicação suporte de tal interpretação (Cf. GUEROULT, I, 1968 p. 9). Segundo o intérprete, a pena do filósofo deve ser a norma da verdade de um adequado entendimento filosófico, e o monumento pelo qual tal filosofia se expressa não deveria ser rodeado por leituras retóricas e criativas. Com outras palavras, em filosofia, não basta alisar o pote, é necessário comer o próprio mel! O esforço do historiador da filosofia é o de desenvolver pesquisas rigorosas que se pautem nos pelos textos filosóficos e que alcancem a estrutura mesma de orientação de tal sistema filosófico. Debates entre intérpretes, fundo histórico (econômico-social-cultural) permitem, ou lançam, as condições históricas do aparecimento de certa teoria. Mas estes são elementos precedidos por uma lógica interna de razões que sustentam determinada concepção filosófica. $\mathrm{O}$ devido lugar de uma obra filosófica remete, pois, a estes dois âmbitos complementares, embora haja a preeminência do elemento estrutural sobre o fundo histórico (econômico-social-cultural).

Diante do disperso e contingente, do complementar e pontual, teríamos, pois, por outro lado, o essencial e fundamental, no caso, a chave interpretativa que permite elucidar uma filosofia em seu âmbito monumental. Nas palavras do intérprete: “O esforço cartesiano se engaja, pois, desde o início, para a constituição de um sistema total de saber certo, por sua vez, metafísico e científico" (GUEROULT, I, 1968, p. 18). O estruturalismo, aqui examinado sob o olhar de Martial Gueroult, defende que toda interpretação filosófica deve dispor os objetos de investigação em seus devidos lugares. Os complementos explicativos possuem importância, evidentemente. A cultura, a economia, a política, as guerras, são elementos agregadores, que elucidam o filosofar por segundo plano. Ocorre que nada suprime a pena do autor! O texto, a obra filosófica, seu entendimento e compreensão rigorosa, segundo este viés interpretativo, é o plano primário e fundante da atividade filosófica. 
Neste sentido, há que se colocar as coisas em ordem. A filosofia como enigma, como movimento de compreensão, remete à análise objetiva de estruturas que manifestam um todo que deve ser coerente segundo certas razões. Conforme Jorge Secada Koechlin, Gueroult buscaria "deixar a descoberto as estruturas demonstrativas da obra cartesiana" (Cf. KOECHLIN, p. VII, In. GUEROULT, 2005, p. VII). É o caso observar que a ordem demonstrativa e estrutural deve voltar-se, sim, à fidelidade histórica de certo entendimento filosófico.

Embora soe belo esse modo majestoso de apresentar a problemática a partir de Gueroult, o problema do anacronismo filosófico parece continuar, pois, como adentrar na chave de leitura que norteia um pensamento filosófico sem lançarmos nosso olhar, sob o viés histórico-social sobre esta teoria que possui uma anterioridade lógica e histórica a nós mesmos? Eis o problema: toda abordagem filosófica está amparada em um entendimento embasado em entes externos ao texto? É possível purgarmos nossa própria historicidade, ou ao menos neutralizá-la?

Cabe, pois, que voltemos a Descartes, e tratemos da busca tão radical e complexa de promover um distanciamento filosófico de nossos prejuízos. Neste caso, se intencionamos evitar o anacronismo, o zelo metodológico faz que devamos distinguir entre a compreensão de uma filosofia no plano especulativo da explicação desta filosofia no plano sistêmico. Diante de duas técnicas fundamentais, Gueroult escolhe aquela que remete à análise sistêmica das estruturas da obra, e que encontra nas Meditações de Filosofia Primeira o essencial da metafísica cartesiana. (Cf. GUEROULT, I, 1968, p. 10). A outra possibilidade, que se detém na crítica dos problemas de fontes, variações de obras e temas, evoluções do pensamento, etc., seria aquela trabalhada por E. Gilson, H. Gouhier e J. Laporte, voltada ao historicismo filosófico. É de observar que esta última vertente, segundo Gueroult, trabalharia por complementaridade, enquanto a primeira seria a fundamental.

Para Gueroult a História da Filosofia também é filosofia, de forma que compreender as cadeias de razões norteadoras do pensar de um filósofo, em sua sistematicidade, supõe entender a ordem das razões que motiva a apresentação organizada dos elementos dispostos, segundo uma ordem da ligação. O encadeamento racional, este nexus, permite fixar o que pertence enquanto verdade a certa teoria filosófica.

De início, já no início de Descartes selon l'ordre des raisons, no capítulo Métaphysique cartésienne et ordre des raisons, toda a crítica à retórica feita por Gueroult parece contraditória, pois a exposição de sua perspectiva, do começo ao fim, tem grande poder retórico e literário, quase ensaiando uma forma artística de tratar Descartes segundo esta interpretação da ordem das razões. Eis o primeiro parágrafo do referido capítulo: 
Há em Descartes uma ideia seminal que inspira toda sua empresa e que exprimiria, desde 1628, em Regras para a direção do espírito, a ideia que o saber tem limites instransponíveis, fundados sobre aqueles de nossa inteligência, mas que no interior destes limites a certeza é inteira. (GUEROULT, I, 1968, p. 14).

Em sua leitura de Descartes, Gueroult se volta ao problema da validade objetiva dos conhecimentos claros e distintos, os quais, na metafísica, deveriam ser fundados sob a inteligência do sujeito pensante e validados pela veracidade divina. O problema é: como é possível que esses limites sejam válidos se a hipótese do grande enganador continua no desvelar da Meditação Segunda, enquanto que é apenas na Meditação Terceira que Deus é provado veraz, e que aí é que a regra que valida indistintamente as ideias claras e distintas é exposta? Eis o círculo cartesiano ${ }^{1}$, problema clássico. É para eivtá-lo na sua interpretação de Descartes que Gueroult promove tamanho esforço intelectual.

A ordem das razões, assim suposta como ordem da justificação, encontraria nas Meditações um caráter essencial, e mesmo, em certo sentido, a-histórico. Nas palavras do intérprete: "A análise do monumento da filosofia cartesiana revela, pois, uma notável coerência" (Ibidem, p. 215). Não é sem razão que esta proposta sistêmica de Gueroult lembra Hegel. Em suas obras Philosophie de l' histoire de la philosophie e Histoire de l' histoire de la philosophie (escritas por GUEROULT respectivamente em 1979; 1984-1985), o historiador da filosofia mostra sua tese de pensar toda filosofia como uma construção sistemática e abstrata. Em seu horizonte interpretativo filosofar supõe, pois, um único e absoluto bloco de certezas, estabelecido conforme a inspiração matemática, assentado sob um encadeamento estrito de razões (Cf. GUEROULT, I, 1968, p. 19).

Notemos que se o Descartes das Meditações segue a ordem das razões e teria alcançado, deste modo, o status de filósofo original, por outro lado, nos Princípios da Filosofia (1644), ele aceita o desafio escolar de escrever conforme a ordem das matérias, tal como os manuais escolásticos. No caso, pensando conforme propõe Soares, o filósofo Descartes, nas Meditações, desenvolveria sua filosofia pautando-se pela espontaneidade imanente ao filosofar, enquanto que o Descartes autor, por sua vez, teria uma motivação doutrinária e dogmática (Cf. SOARES 2008). Haveria, pois, esta dualidade na escrita de Descartes, oscilando entre o aspecto criativo e o âmbito doutrinário de seu pensamento.

\footnotetext{
${ }^{1}$ Seguiremos, tanto quanto possível, o modo standard de citação de obras de Descartes: Em primeiro lugar as letras "AT", considerando a edição Adam - Tannery, seguido do número do volume e das páginas correspondentes, sem que mencionemos, por economia, o nome do autor. Quando necessário, seguir-se-á a referência da edição traduzida. Sobre o círculo cartesiano, eis a interessante crítica de Arnauld nas Objeções e Respostas: AT, VII, 214; AT, IX, 89-90.
} 
Gueroult pensa a filosofia cartesiana em outros termos, considerando como um núcleo as Meditações, do qual em leque as demais obras de Descartes seriam dependentes, ao mesmo tempo que contribuiriam de forma suplementar, sempre se remetendo ao núcleo. Quanto ao método, o da análise, o intérprete relaciona a proposta cartesiana como seguindo fielmente a obra Elementos de Euclides, de forma que a ordem das matérias, exposta nos Princípios da Filosofia, seria oposta àquela, pois proporia dissociar temas, voltando-se à questão pedagógica, enquanto que a ordem das razões, por sua vez, demonstraria o encadeamento lógico das descobertas, pois "as coisas que são propostas primeiro devem ser conhecidas sem a ajuda das seguintes, e que as seguintes devem ser dispostas de tal modo que elas sejam demonstradas unicamente por aquelas que as precedem" (Respostas às Segundas Objeções, AT, IX, p. 121).

Voltando ao texto de Gueroult, no capítulo segundo do volume primeiro, por exemplo, em que temos a temática da dúvida e do gênio maligno, percebemos um modo determinado e confiante de expor sua chave de leitura, vejamos:

As Meditações se desenvolvem em conformidade às regras de um método que prescreve seguir o encadeamento necessário das razões. Elas parecem, por consequência, dever ser justificáveis pela validade deste método, já constituído antes delas. De outra parte, as conclusões às quais elas nos conduzem seriam sem força se a validade deste método não fosse firmemente estabelecida (GUEROULT, I, 1968, p. 30).

Nas Meditações Descartes quer provar a existência da alma e a natureza do sujeito pensante, provar a existência de Deus, provar a distinção real entre a alma e o corpo do homem, provar a existência dos corpos, e tudo isso seguindo as razões da luz natural e utilizando o ceticismo como procedimento inicial de crítica aos prejuízos. Para tanto, o filósofo dispõe de um método, mas qual? A resposta, nas palavras de Descartes: "o método, que ensina a seguir a verdadeira ordem e a enumerar exatamente todas as circunstâncias do que se busca, contém tudo o que dá a certeza às regras da Aritmética (AT, VI, p. 21; Discurso do método). Notemos que Gueroult parte desta questão primogênita sobre o método, e a partir de sua posição quanto a ela edifica uma complexa e ampla interpretação da obra de Descartes, em especial das Meditações, justificando-a segundo um rigor matemático que orientaria toda a empresa cartesiana. Segundo a organicidade desta forma em cadeia de interpretar, apresenta ao fim de seu segundo volume do Descartes selon l' ordre des raisons o que seriam as doze verdades capitais. Estas verdades são um mapeamento crítico e rigoroso, resultante de sua análise estrutural, a qual manifesta o essencial do sistema filosófico de René Descartes. Vejamo-las em conjunto, conforme a ordem proposta pelo autor e segundo os propósitos filosóficos, didáticos e historiográficos do presente artigo. 
Doze verdades da metafisica cartesiana, segundo a ordem analítica das razões (Cf. GUEROULT, II, 1953, Cap. XVIII, p. 217-218):

1) Certeza absoluta da existência de meu eu como pensamento (verdade subjetivamente e objetivamente necessária);

2) Conhecimento certo de minha natureza como inteligência pura; critério da substancialidade (verdade subjetivamente necessária);

3) Prioridade certa do conhecimento da alma sobre aquele do corpo (demonstração subjetivamente necessária; do princípio que do conhecer ao ser a consequência é boa);

4) Valor necessariamente objetivo da ideia de perfeito, ou existência absolutamente indubitável de Deus como causa, por sua vez, eficiente e exemplar desta ideia em mim (verdade subjetivamente e objetivamente necessária). A partir daí todas as verdades demonstradas serão, no caso, subjetivamente e objetivamente necessárias.

5) Existência indubitável de Deus como causa de si, e criador de meu ser;

6) Certeza da veracidade divina: valor objetivo imediatamente certo de todas as ideias claras e distintas; valor objetivo presumido de outras ideias, enquanto que elas contêm qualquer realidade objetiva; conversão de todas as verdades subjetivamente necessárias de minha ciência em verdades objetivamente necessárias, ou verdades das coisas;

7) Compatibilidade da veracidade divina e do erro humano (solução do problema de teodiceia);

8) Conhecimento do mecanismo do erro humano: o livre arbítrio humano, fonte do erro formal (solução do problema psicológico). Esta verdade e a precedente constituem a solução do problema do erro relativo às ideias do entendimento;

9) Consequências de nossa certeza concernente ao valor objetivo das ideias claras e distintas: conversão destas ideias em essências, certeza absoluta que as propriedades destas essências (das coisas matemáticas ou de Deus) são as propriedades mesmas das coisas, de onde a validação da prova a priori da existência de Deus: certeza absoluta da existência necessária, pois eterna, de Deus;

10) Valor objetivo da distinção necessária das substâncias: certeza absoluta da distinção real da alma e do corpo;

11) Valor objetivo das ideias sensíveis nos limites de sua realidade objetiva e de sua região: A) valor objetivo da realidade objetiva, do constrangimento da variedade do sentimento; o sentimento como signo indubitável da existência das coisas materiais e de suas diferenças em si; as coisas materiais como causas ocasionais indubitáveis 
do sentimento: certeza absoluta da existência dos corpos. Diferentes graus de certeza absoluta;

12) B) Valor objetivo (sucedâneo deste valor) da qualidade (do obscuro e do confuso): certeza absoluta da união substancial da alma e do corpo: a) união da alma com todas as partes do corpo; b) união da alma, mais particularmente com uma das partes do corpo. Solução do problema do erro na região dos sentidos.

Para Gueroult a compreensão sistêmica de uma obra filosófica remete ao encadeamento lógico de teses ou verdades atemporais que permitem a elucidação de um dado pensamento. Em bloco, certas teses relacionadas, encadeadas e dependentes entre si, fazem um todo monumental, no qual cada parte está voltada ao todo, a um sentido capital e originário que orienta todo o edifício de dada teoria filosófica. O método diretriz, no caso de Descartes e das Meditações, seria, como já salientamos, a ordem das razões. Diante maneira de apresentar e organizar o pensamento de Descartes, a crítica a Gueroult, no Brasil, é um tema já abordado por Lívio Teixeira (Cf. 1990), o qual tem uma importante interpretação voluntarista sobre a moral de Descartes. Raul Ferreira Landim Filho, em sua obra Evidência e verdade no sistema cartesiano (Cf. 1992), por sua vez, mostra a constituição das noções de certeza, verdade e evidência, de forma sucinta e lúcida. Já Zeljko Loparic, em seu livro Descartes heurístico (Cf. 1997), trabalha temas ligados ao que seria uma "eurística cartesiana", e aponta algumas críticas à obra de Gueroult segundo esta chave de leitura.

Entre tantas críticas feitas à interpretação gueroultiana, o livro de César Augusto Battisti (2010) apresenta estudos sobre o método cartesiano a partir do modo resolutório de lidar com problemas, contrastando, como se percebe, ao que propõe Gueroult. Para Gueroult a totalidade e sistematicidade do pensamento de Descartes se manifesta por um nexus que dispõe e organiza os problemas, temas e verdades segundo uma dada ordem da descoberta. Por sua vez Battisti mostra que a ordem das descobertas é rigorosa, mas possui certos aspectos ocasionais diante das temáticas resolutórias. Assim, enquanto o primeiro organiza as discussões segundo um nexus sistêmico estrutural e atemporal, o segundo considera que esse nexus sistêmico é dinâmico e temporal. Ademais, estudioso da matemática de Descartes, à luz dos ensaios introdutórios ao método, no caso, a Dióptrica, Meteoros e Geometria, Battisti mostraria que a inspiração matemática de Descartes seria muito mais apegada a Pappus que a Euclides, como supõe Gueroult!²

No seio de tal controvérsia, quanto ao tema, talvez a fonte da proposta gueroultiana não seja fidedigna à pena de Descartes, pois, segundo Bat-

\footnotetext{
${ }^{2}$ Para quem interessar, conferir o interessante artigo de Battisti que aborda a interpretação matemática gueroultiana, remetendo ao método cartesiano em relação ao teorema de Pitágoras apresentado por Euclides: Cf. BATTISTI, 2014.
} 
tisti, o intérprete francês não cita e não "examina o texto dos Elementos em nenhuma ocasião, por mais que não se furta em estabelecer uma tese absolutamente forte entre as Meditações e os Elementos"3 (BATTISTI, 2016, p. 200). A inspiração matemática, tão defendida por Descartes e interpretada por Gueroult, está posta nesta situação singular de ligar a axiomática geométrica de Euclides com a ordem das razões tal qual expõe Gueroult.

Em relação ao "interpretar de forma fiel e em consonância à pena do autor", algo que é tão defendido por Gueroult ao longo de seus estudos, também no caso da interpretação do cogito e da teoria cartesiana da verdade, temos outra controvérsia interessante. Diante do subjetivismo do sujeito pensante, quando ele toma ciência de sua existência como coisa pensante ( $\$ 4$ da Meditação Segunda), Gueroult, na sua luta interpretativa por evitar circularidade em Descartes, estabelece uma distinção entre "ciência para mim" - ou "minha ciência" e "ciência em si" (GUEROULT, I, 1968, p. 6263). Examinando este tema, Forlin defende que

[...] Gueroult cinde também em duas a noção cartesiana de verdade: uma que se identificaria com a necessidade para o sujeito e que Gueroult chama de "certeza objetiva"; a outra sendo a verdade propriamente dita, isto é, a correspondência entre a idéia e a realidade exterior que ela representa. É essa cisão genérica que Gueroult opera no sistema metafísico de Descartes que consideramos, por assim dizer, uma leitura "kantianizada" de Descartes (FORLIN, 2005, p. 16-17).

Considerando as teses I, II e III, temos no livro de Enéias Forlin A Teoria Cartesiana da Verdade (2005), uma crítica direta à interpretação gueroultiana de conceber uma cisão no cogito, em que o sistema metafísico do filósofo francês estaria dividido em dois momentos: 1) do cogito à prova da existência de Deus, embasado em uma ciência de certezas objetivas, ou ciência "para mim"; 2) da primeira prova da existência de Deus até o fim das Meditações, tratando, pois, da ciência em si, com valor objetivo. (Cf. FORLIN, 2005, p. 16).

A leitura de Gueroult, segundo a crítica de Forlin, erraria por cindir a noção cartesiana de verdade, sobretudo por tematizar Descartes segundo uma compreensão anacrônica e "kantianizada". A solução de Forlin é

\footnotetext{
${ }^{3}$ Segue a nota explicativa de Battisti, parafraseando Gueroult, no sentido de mostrar como tal interpretação estabelece uma ligação radical entre as Meditações e os Elementos: "O modelo que seguirá o filósofo [Descartes] não será mais o Tratado de Filosofia, dividido em capítulos, ou a Summa, com suas questões e seus artigos, mas os Elementos de Euclides" (GUEROULT, 1953, 1, p. 20); "As seis Meditações não são senão a réplica metafísica dos Quinze Livros dos Elementos de Euclides. Se as noções de que elas tratam pudessem, como os conceitos da geometria, apoiar-se na imaginação, em vez de serem contrariadas por ela, as Seis Meditações, elas mesmas, não seriam senão livros como aqueles de Euclides" (GUEROULT, 1953, 2, p. 200); Cf. BATTISTI, 2014, p. 200, nota 97.
} 
considerar a teoria cartesiana da verdade a partir do correspondencialismo cartesiano, pois dessa forma:

1) ela obteve sua validade pela via da intuição intelectual, e não da percepção sensível, isto é, por uma via totalmente diferente daquela a que habitualmente estava associada; 2) não se trata mais, portanto, de situá-la numa relação de exterioridade entre nossas opiniões e as coisas que nos cercam, mas de situá-la, a partir da interioridade da consciência, numa relação entre nossas idéias e as coisas exteriores que estão para além delas; 3 ) tudo isso implica a articulação da noção de verdade por correspondência numa relação entre três termos, isto é, na relação entre opinião, idéia e realidade exterior; 4) por fim, o critério de verdade deixou de ser a experiência sensível para se converter fundamentalmente na percepção clara e distinta da mente. (FORLIN, 2005, p. 335-336).

Como ensaiar justificar a opinião de Gueroult, segundo o qual há na obra de Descartes um rigor explicativo de inspiração geométrica, uma filosofia monumental e sistêmica, fiel seguidora de Euclides, embora na sua obra o filósofo pouco cite os Elementos? (Tese crítica de Battisti). E na edificação de um sistema filosófico completo e coerente, que não seja anacrônico, como legitimar esta suposta "kantianização" de Descartes a partir de uma distinção entre "ciência para mim" e "ciência em si"? (Tese crítica de Forlin). Interessante é, de todo modo, que a chave de leitura gueroultiana propõe um exame amplo e profundo, exaustivo, competente e criativo, ao passo que de fato ele trata os temas passo a passo, quase parágrafo a parágrafo, no caso específico das Meditações.

Algo extremamente notável é quão estudada é a interpretação de Gueroult no Brasil e no mundo. Naturalmente, pois, ela torna-se um cobiçado alvo dos estudiosos de Descartes. Seu rigor estrutural e compreensivo se vê marcado pelo que alguns apontam ser uma certa negligência quanto às fontes históricas, visto que há, na escrita do intérprete, uma inventividade, uma capacidade criadora e articuladora que reúne e elucida elementos de uma teoria segundo determinados fios condutores. ${ }^{4}$ A questão que se apresenta é: tais fios condutores são invenções, criações e anacronismos? Ou eles são fidedignos e permitem um interpretar Descartes puro, tanto quanto é possível fazê-lo?

\footnotetext{
${ }^{4}$ Entre outras passagens em que se manifesta o caráter "criativo" na interpretação de Gueroult, citamos: "[...] se deve supor, ante todo exame, que uma tese enunciada ante uma outra é condição desta outra; tal é, por exemplo, o caso da prova de Deus pelos efeitos que, precedendo a prova ontológica, deve dela ser considerada como a condição, ao ponto que a última, separada da primeira, perde toda a sua validade. É também em virtude da ordem que Descartes estima necessário colocar $<<$ as coisas que devem ser consideradas separadamente com as outras...em Meditações separadas >>. É importante, pois, examinar as questões que são agrupadas em cada Meditação para saber imediatamente que elas são inseparáveis e estão situadas todas juntas no mesmo local da cadeia das razões". (GUEROULT, 1968, p. 21).
} 
Embora as críticas de Battisti e Forlin sejam muito interessantes, uma crítica mais comum e que também parece pôr em xeque a interpretação gueroultiana é a que remete às provas da existência de Deus. No caso, todas as teses apresentadas no mapeamento de Gueroult estão relacionadas umas às outras e são interdependentes. Isso significa que elas tratam de problemas específicos e possuem suas peculiaridades; porém, tais segmentações são secundárias em relação ao todo sistêmico ao qual elas se ligam. Diante desta organização sistêmica, as teses IV, V, VI, VII, VIII e IX, todas elas remetem diretamente à questão da veracidade divina. A ordem e o papel das provas da existência de Deus são tema de profunda discussão na historiografia filosófica de Descartes. Para Gueroult as provas causais deveriam vir primeiramente, por uma necessidade metafísica, enquanto que a prova ontológica seria insuficiente para existir por si mesma, conforme bem comenta Jorge Secada Koechlin (Cf. KOECHLIN, p. XLII. In. GUEROULT, 2005, p. XLII). O que Gueroult pretende é mostrar a estrutura da razão e sua validade por meio de uma explicação que supere a crítica do círculo cartesiano, tão tradicional desde as Objeções e Respostas 5 .

Outro ponto capital da interpretação gueroultiana e que parece elencar problemas é sua abordagem do composto substancial, do papel da moral e da ligação das Meditações com o Discurso do Método, Princípios da Filosofia, Correspondência e as Paixões da Alma. Para o intérprete francês a medicina e a moral seriam técnicas para o bem da vida presente, baseadas no princípio do melhor. Assim, na passagem da metafísica para essas ciências, a região do sentimento, em suas especificidades, teria na moral uma técnica voltada ao alcance da felicidade e na medicina ao cuidado com o corpo, mas no âmbito do obscuro e confuso (Cf. GUEROULT, II, 1953, Cap. XIX). Neste caso, a psicologia apareceria como um instrumento da moral, enquanto que a metafísica superaria essa vulgaridade de uma psicologia comum, o que nos parece contradizer a pena do filósofo.

Há uma tradição consolidada, baseada em Gueroult e Gilson, que trata o reino do sentimento e da vida comum em função das categorias de obscuridade e confusão, tal qual essas aparecem na Meditação Sexta. ${ }^{6}$ Tal

\footnotetext{
${ }^{5}$ Cf. o famoso círculo de Arnauld, em sua famosa crítica à Descartes: AT, VII, 214; AT, IX, 89-90.

${ }^{6}$ Particularmente Étienne Gilson contrapõe a antropologia cartesiana e a tomista, mostrando um paradoxo, o qual ele afirma ser uma cicatriz ou chaga do sistema cartesiano, pois remeteria a uma circularidade posta no âmago da união substancial. Diz Gilson que "a necessidade na qual estamos de unir a alma e o corpo é exatamente proporcional à necessidade que nós temos de os distinguir". Permaneceria uma suposta "dubiedade" que comprometeria o pensamento de Descartes como um todo. Cf. GILSON, 1984, Parte II, Cap. VII, p. 245. O intérprete aponta que o rigor lógico da metafisica das Meditações supõe que temos ideias distintas da alma e do corpo porque ambos existem, porém, como a existência real dos corpos se apoia no conhecimento sensível, e este é confuso e involuntário, esta confusão do conhecimento de duas naturezas que são distintas, leva à situação de a prova cartesiana da existência do mundo exterior implicar na própria união da alma e do corpo, o que seria
} 
interpretação entende que o estatuto do bem e da humanidade do homem estaria no âmbito do provisório e da incerteza, o que parece dirimir a importância da moral. Para Descartes a psicologia racional é esboçada no Discurso do Método, e se constituí de forma acabada nas Meditações, desenvolvida e complementada com as Objeções e Respostas, Princípios da Filosofia, as Cartas e com o tratado Paixões da Alma. Sua transposição para o terreno da moral não é um salto para uma região ontológica inferior, mas remete ao composto substancial, ao homem completo e inteiro que é objeto fundamental da metafísica, da física e da moral. Entre estoicismo, epicurismo, terapêutica médica, crítica à escolástica, eudaimonismo, a teoria da virtude e do contentamento não parte de uma limitação tal que a natureza humana seria um obstáculo à verdade. Segundo entendemos, para o filósofo há complementaridade e cumplicidade entre metafísica, física, psicologia da vida comum e moral.

É equivocada a tese de secundarizar a moral ou tratá-la como inferior no amplo quadro do pensamento de Descartes. Desde o Discurso do Método, escrito em 1637, com a defesa e divulgação de um caminho para a condução da razão através do método e a busca pela verdade nas ciências, o filósofo enfatiza que ao tratar de considerações diversificadas sobre a ciência, tema da primeira parte, e logo ao expor as principais regras do método, tema da segunda parte, a terceira parte apresenta as regras da moral tiradas do método, a quarta parte mostra as razões pelas quais o autor prova a existência de Deus e da alma humana, a quinta parte trata de questões de física, movimento do coração, medicina, etc., a sexta parte trata de elementos para progredir na pesquisa da natureza. Notemos que neste amplo horizonte investigativo, ele enlaça o método, a ciência, a metafísica e a moral. Tanto é assim que na Carta Prefácio aos Principios da Filosofia Descartes expõe de forma acurada esta visão sistêmica e organicista do saber ${ }^{7}$. Entendemos, dessa forma, que a temática da moral é central na obra de Descartes desde 1637, tanto é assim que a moral provisória é exposta como fundamental, pois permite a orientação para o bem viver, ainda que a metafísica, considerando a exposição metafísica das verdades do ser e do conhecer, seja edificada em sentido rigoroso em 1641, com as Meditações.

Citações expostas segundo articulações criativas, manobras e esquemas conceituais sofisticados para tudo caber racionalmente, segundo um sentido interno rigoroso das razões, todas estas críticas polêmicas que poderíamos

circular e prejudicaria toda a explicação. Assim, se a prova da existência do mundo exterior tem por fim estabelecer a distinção real da alma e do corpo, concluía-se dessa relação que a prova da distinção real se apoiaria necessariamente sobre o fato de sua união, o que seria circular. Schirmer e Landim mostram, cada qual ao seu modo, maneiras de interpretar o tema que se opõem a esta noção de paradoxo cartesiano exposta por Gilson. Cf. Respectivamente: SCHIRMER, 2003; LANDIM, 1997.

${ }^{7}$ Cf. AT, IX-2, p. 1. 
lançar contra a interpretação gueroultiana, parecem menos fortes, segundo nosso entendimento, que o evidente tratamento secundarizado da temática moral. Em metafísica, um detalhismo assombroso, em moral, apontamentos "en passant" ou tratados como elementos secundários. Quanto ao tema da moral, voltemos às doze verdades da metafísica cartesiana, segundo a ordem analítica das razões na visão gueroultiana, tal qual o intérprete as expõe.

No item VIII, por exemplo, ao abordar o "conhecimento do mecanismo do erro humano: o livre arbítrio humano, fonte do erro formal", não se trata apenas de mostrar que o livre arbítrio possui uma duplicidade: de um lado, a fonte do erro - âmbito formal, e, de outra parte, a possibilidade do erro no julgamento como uma necessidade para que haja a liberdade humana. A própria liberdade é condição sine qua non para que o pensar não seja reduzido a um receptáculo, mas que ele possa manifestar intenções e julgamentos. É pela complementaridade entre as faculdades do intelecto e da vontade que o intelectualismo é suplementado e alimentado pelo voluntarismo, montando assim, o arcabouço fundamental para que a liberdade se manifeste enquanto moral. É interessante que voltemos à descoberta do ser pensante para melhor apresentarmos essa questão.

O cogito é apreendido ou descoberto no $\$ 4$ da Meditação Segunda. Há, pois, uma investigação sobre a natureza desta res cogitans (coisa pensante) que se descobriu, em um primeiro momento, como puro pensamento. $\mathrm{O}$ sujeito se reconhece como ego cogitans (eu pensante), e, deste modo, inicia uma estratégia filosófica radical, que é posta como uma inspeção do espírito. Esta nada mais é que a investigação de si mesmo supondo a máxima de aceitar algo como verdadeiro apenas se ele se mostrar indubitável.

Mais adiante, isto é, no $\$ 12$ da Meditação Segunda, a argumentação que explicita a percepção da cera como um poder intelectual de conhecer ou conceber (poder de inteligir) ${ }^{8}$, tal capacidade se remete à atualização de uma certeza: aquela do cogito. No caso de tal temporalidade, a qual manifesta uma continuada atualização dessa certeza no curioso caso do exame da cera, é manifesto que o sujeito do pensar é uma unidade indissolúvel e originária, e, como tal, nele todos os atos representativos são percepções imanentes ao sujeito pensante. Tal situação é explicitada pelo filósofo da seguinte forma: essa é a razão pela qual "pode acontecer que aquilo que vejo não seja de fato cera; pode também dar-se que eu não tenha olhos para ver coisa alguma; mas não pode ocorrer, quando vejo ou (coisa que não mais distingo) quando penso ver, que eu, que penso, não seja alguma coisa" $^{\prime \prime}$. Essa situação mostra que o pensar como sentir sempre se remete

\footnotetext{
8 “[...] não poderia mesmo conceber pela imaginação o que é essa cera e que somente meu entendimento é quem o concebe" (AT, IX-1, p. 24).

${ }_{9}^{9}$ AT, IX-1, p. 25; Obras escolhidas, 2010, p. 149.
} 
à unidade do espírito, de tal maneira que ali esteja suposta a substancialidade da alma. Conforme diz Descartes:

[...] a alma humana não é composta de quaisquer acidentes, mas é uma pura substância. Pois, ainda que todos os seus acidentes se modifiquem, por exemplo, que ela conceba certas coisas, que ela queira outras, que ela sinta outras etc., é, no entanto, sempre a mesma alma. (AT, IX-1, p.10)

O poder de inteligir e os atos de julgamentos manifestam-se por meio da unidade do espírito. A concepção do entendimento e o julgamento da vontade formam um todo que associa o recebimento da percepção e a execução intencional de julgamentos. Isso é mostrado em uma passagem do $\S 14 \mathrm{em}$ que se discute um exemplo que pode ser considerado um complemento do exemplo da cera. Eis o que afirma o filósofo no §14:

[...] pelos termos da linguagem comum; pois nós dizemos que vemos a mesma cera, se no-la apresentam, e não que julgamos que é a mesma, pelo fato de ter a mesma cor e a mesma figura: donde desejaria quase concluir que se conhece a cera pela visão dos olhos e não somente pela inspeção do espírito, se por acaso não olhasse pela janela homens que passam pela rua, à vista dos quais não deixo de dizer que vejo homens da mesma maneira que digo que vejo a cera; e, entretanto, que vejo desta janela, senão chapéus e casacos que podem cobrir espectros ou homens fictícios que se movem apenas por molas? Mas julgo que são homens verdadeiros e assim compreendo, somente pelo poder de julgar que reside em meu espírito, aquilo que acreditava ver com meus olhos. (AT, IX-1, p. 25)

Na passagem acima a intuição é apresentada como complementada pelo poder de julgar. O julgamento é, pois, o âmbito no qual o erro e o acerto se manifestam enquanto deliberação do sujeito. A expressão final da passagem mostra que "julgo que são homens verdadeiros e assim compreendo, somente pelo poder de julgar que reside em meu espírito, aquilo que acreditava ver com meus olhos".

Quanto ao assunto, a Meditação Quarta trata da liberdade e do papel da faculdade da vontade. E tais temas, preeminentes em relação à compreensão de todo o sistema cartesiano, não são, ao que nos parece, devidamente problematizados na compreensão esquemática gueroultiana. Embora metafísica, para o filósofo, seja ciência dos fundamentos e trate dos princípios do ser e do conhecer, o intelectualismo cartesiano jamais esteve destoado do voluntarismo e da moral, pois o ego cogitans é um puro ser pensante que sente e que quer. Este querer sempre implica, de um modo ou de outro, julgamentos morais. A moralidade, pois, sempre está suposta. Neste caso, enquanto o entendimento compreende, apreendendo significativamente certos conteúdos, é a faculdade da vontade que manobra percepções/objetos intelectuais que são recebidos primeiramente pelo entendimento. 
Para Gueroult a aceitação do provável, como princípio do melhor, mostraria o limite da moral, enquanto ciência das paixões (GUEROULT, II, 1958, p. 242). Se o entendimento se mantém sem a vontade, mas não o contrário, a questão da medicina e da moral como ciências auxiliares mostraria que a cientificidade da moral é limitada, e embora opere como coroamento do sistema, teria uma certa abertura para o obscuro e confuso, tal que extrapolaríamos o âmbito da verdade para alcançarmos aquele da utilidade. Eis o que o intérprete diz textualmente sobre a medicina e a moral: "A respeito de uma conduta (médica ou moral) cientificamente boa, se deverá optar pelo <melhor possível>" (GUEROULT, II, 1958, p. 246). Ora, essa explicação segundo o "princípio do melhor" é marca da interpretação gueroultiana acerca da moral. Essa visão sistêmica, dedutivo-racional de todo o pensamento de Descartes, se não peca em rebaixar o estatuto da moral, certamente, nos parece, a secundariza. Podemos observar tal posicionamento, por exemplo, na passagem abaixo:

[...] as disciplinas racionais concernentes à vida, sua conservação e a felicidade da alma na vida presente (a beatitude), sejam concebidas em função de três ideias muito diferentes: segundo a ideia de uma ciência muito exata, de tipo matemático-dedutivo, derivada da física, segundo a ideia de uma ciência psicológica e psicofísica clara e distinta tomando apoio sobre as certezas do sentimento (em si obscuro e confuso), na região da substância psicofísica, segundo a ideia de um corpo de princípios gerais assegurados, destinados à suprir a carência, ao menos parcial, destas duas ciências, e próprias à nos guiar no meio de nossas incertezas. (GUEROULT, II, 1958, p. 247).

É notório o caráter auxiliar atribuído à medicina e à moral, posicionando-as como disciplinas no mesmo patamar, o que parece contradizer o aspecto enfático da moral como "a mais perfeita moral", quando o filósofo afirma na Carta Prefácio aos Princípios da Filosofia que ela seria o último grau da sabedoria. Vejamos o que nos diz Descartes:

[...] toda a filosofia é como uma árvore, cujas raízes são a metafísica, o tronco é a física, e os braços que saem deste tronco são todas as outras ciências, que se reduzem a três principais, à saber, a medicina, a mecânica e a moral; eu entendo a mais alta e a mais perfeita moral que pressupõe um inteiro conhecimento das outras ciências, é o último grau da sabedoria. (AT, IX-2, p. 14).

A moral é o "último grau da sabedoria", o qual, é verdade, supõe o "inteiro conhecimento das outras ciências". Concordamos que há organicidade no pensamento de Descartes; porém, a teoria cartesiana do homem, baseada na mais perfeita moral, posiciona-se de forma a mostrar como o composto substancial, ou a unidade da pessoa, possui, no tocante às paixões, uma ciência de seu conhecimento, manuseio e administração, daí permitindo o aperfeiçoamento moral através de uma teoria da virtude e do contentamento. Aqui está o último grau da sabedoria, e não na metafísica, como parece sugerir a exposição gueroultiana! 
A explicação do fenômeno passional, tema extremamente intrincado, ocorre sob um duplo aspecto: por um lado, há uma investigação de caráter descritivo, a qual permite entender o fenômeno passional em âmbito "físico", ou como "physicien", e, por outro lado, a maestria das paixões permite o aperfeiçoamento humano em vista da constituição de uma moral para a generosidade. É por meio da generosidade, tema central das Paixões da Alma, que se pode "excitar em si a paixão e, em seguida, adquirir a virtude da generosidade, a qual sendo como a chave de todas as outras virtudes e um remédio geral contra todos os desregramentos das paixões, me parece que esta consideração bem merece ser observada" (AT, XI, p. 454).

No título do artigo 30 da obra Paixões da Alma, Descartes enfatiza que "a alma está unida a todas as partes do corpo conjuntamente"10. E o filósofo afirma que a união "é substancial e não acidental, a alma e o corpo formam um só todo, uma terceira substância"11. A interação substancial entre alma e corpo, a partir da experiência psicofísica e psicossocial, ocupa papel central na fase madura da obra do filósofo. Após expor sua metafísica ao grande público (Discurso do Método), a exposição metafísica dos fundamentos do ser e do conhecer (Meditações), o embate com os objetores (Objeções e Respostas), a escrita de um tratado que apresenta seu pensamento de forma organizada em matérias (Princípios da Filosofia), por fim, ao manter uma rica correspondência, principalmente com Elisabeth, o filósofo enfrenta o que poderia ficar como o "calcanhar de Aquiles" de sua filosofia: ele decide aprimorar sua obra e refinar esta antropologia que trata do dualismo substancial, ligando metafísica, física e moral, segundo uma teoria das paixões razoavelmente bem circunscrita. Eis o papel fundamental do tratado Paixões da Alma.

Esta antropologia que se manifesta na obra de Descartes pauta-se, evidentemente, pela abordagem substancial do dualismo metafísico, que é a sua base. Mas, reiteramos, é pela investigação das paixões que se mostra como uma alma está unida ao corpo na própria efetividade da vida de um homem. Assim, se existe, efetivamente, uma enorme dificuldade em explicar a ação recíproca entre duas coisas distintas que habitam substancialmente um mesmo ser, por outro lado, é inegável que a filosofia madura de Descartes se ocupou minuciosamente com o problema do dualismo rígido a partir de uma teoria da efetividade das vivências humanas, segundo a descrição e investigação do fenômeno passional. $\mathrm{O}$ elo que estabelece essa ponte é a moral, e ela é, certamente, o coroamento do pensamento de Descartes, pois é o mais alto grau da sabedoria. ${ }^{12}$

${ }^{10}$ AT, XI, p. 351.

${ }^{11}$ AT, VII, p. 81; AT IX, p. 64 - Sextas Respostas.

${ }^{12}$ AT, IX-2, p. 14. 
Nós sabemos que a vida de um homem não é o ajuntamento mecânico de uma alma a um corpo. É justamente sob o auspício da delimitação metafísica que a teoria das paixões apresenta estratégias para que a alma possa usar todos os meios de que dispõe para se tornar mestra de suas paixões (tema do Art. 50: Que não há nada na alma tão fraco que ela não possa, sendo bem conduzida, adquirir um poder absoluto sobre suas paixões - AT, XI, p. 368-369). Ocorre que a alma e o corpo podem agir a favor ou contra o outro, de modo que a unidade substancial possui um pano de fundo relacional, o qual sempre implica mecanismos de interação. A moral, no tratado Paixões da Alma, surge, então, englobando uma antropologia que renova a moral provisória do Discurso do Método, o que é muito bem exposto na Segunda Carta Prefácio ao Tratado Paixões da Alma (Agosto de 1649) onde o filósofo explica que "[...] meu desejo não é de explicar as paixões como orador, nem mesmo como filósofo moral, mas somente como physicien" (AT, XI, p. 326).

Esse limite exposto é enigmático. Na verdade Descartes tratará de várias coisas, e, entre elas, temos a exposição de sua moral a partir de uma teoria da virtude e do contentamento, segundo a noção de generosidade, atrelada ao âmbito científico do fenômeno passional ${ }^{13}$, mostrando o próprio fenômeno em âmbito somático e relacional ao que se manifesta na alma como paixão da alma. O entendimento de como ocorrem as ações dos "espíritos animais" sobre a alma e de que forma lidar com elas é um grande desafio, o qual foi explorado cientificamente, inclusive apresentando a glândula pineal como um âmbito de ligação entre o somático e o espiritual. Como os animais não experimentam as paixões (Art. 50 das Paixões da Alma), só o homem possui a experiência passional. É nela que a verdadeira experiência do dualismo metafísico tem sua razão de ser.

\section{Referências bibliográficas}

ALQUIÉ, Ferdinand. La découverte métaphysique de l'homme chez Descartes. Paris: Presses Universitaires de France, 1950.

BARON, Jan-Louis Vieillard (Org.). Le problème de l'âme et du dualisme. Paris: Librairie Philosophique J. VRIN, 1992.

BATTISTI, César Augusto. Sujeito em Descartes: ser pensante e corpo. In: Às voltas com a questão do sujeito - posições e perspectivas. Ijuí, RS/Cascavel, PR: UNIJUí/ EDUNIOESTE, 2010.

\footnotetext{
${ }^{13} \mathrm{O}$ Art. 27 da obra nos apresenta uma definição importante para o tema: as paixões da alma são "as percepções, ou os sentimentos, ou as emoções da alma, que relacionamos particularmente a ela, e que são causadas mantidas e fortificadas por qualquer movimento dos espíritos" (AT, XI, p. 347).
} 
. O método de análise em Descartes: da resolução de problemas à constituição do sistema do conhecimento. (Série Estudos Filosóficos oํ 5). Cascavel, PR: EDUNIOESTE, 2002.

- Nota crítica à compreensão de Gueroult do teorema de Pitágoras apresentado por Euclides. In: Analytica. Rio de Janeiro, v. 18, n. 2, p. 153-204, 2014.

BEYSSADE, Michele. A Dupla Imperfeição da idéia Segundo Descartes. Tradução: Marcos André Gleizer. In: Analytica. Rio de Janeiro, v. 2, n. 2, p. 37-49, 1997.

BEYSSADE, Jean Marie. A teoria cartesiana da substância. Equivocidade ou Analogia? Tradução: Lia Levy. In: Analytica. Rio de Janeiro, v. 2, n. 2, p. 11-36, 1997.

BEYSSADE, J-M; MARION, J-L (Org.). DESCARTES. Objecter et Répondre. Paris: Presses Universitaires de France, 1994.

DESCARTES, R. CEuvres. Publiées par Charles Adam et Paul Tannery, 11 vol.,19738. Paris: Vrin, 1996.

.Ouvres Philosophiques de Descartes. (O.P.D.), (Org.). Ferdinand Alquié.3 vol. Vrin: Paris, 1967.

. Discurso do método; Meditações; Objeções e respostas; As paixões da alma; Cartas. (Coleção Os Pensadores). 2. ed. São Paulo: Abril Cultural, 1979.

- Meditações sobre Filosofia Primeira. Tradução: Fausto Castilho. Ed. Bilíngüe em latim e português (Coleção Multilíngües de Filosofia Unicamp - Série A - Cartesiana I). Campinas, SP: Editora da Unicamp, 2004.

Obras filosóficas: objeciones e los princípios de la filosofia. Introdução: Étienne Gilson. Versão espanhola: Manuel de La Revilla. Buenos Aires: Editorial El Ateneu, 1945.

. Princípios da filosofia. Tradução: João Gama. Lisboa: Edições 70, 1997. ções 70, 1989.

Regras para a direção do espírito. Tradução: João da Gama. Lisboa: Edi-

FORLIN, Enéias. A teoria cartesiana da verdade (Coleção Filosofia n. 14). São Paulo: Associação Editorial Humanitas; Ijuí: Editora Unijuí/ Fapesp, 2005

. O argumento cartesiano do sonho. In: Discurso. Revista do Departamento de Filosofia da Usp. São Paulo: E. Discurso Editorial, n. 32, p. 235-248, 2001.

. O papel da dúvida metafísica no processo de constituição do cogito. São Paulo: Associação Editorial Humanitas, 2004.

- O Princípio-Fantasma da Meditação Terceira: esclarecimento sobre os termos de formulação da prova cartesiana do valor objetivo de nossas idéias. In: Necessidade e Eternidade. Campinas, SP: Unicamp-IFCH, p. 109-161, 2008.

GILSON, E. Études sur le rôle de la pensée médiévale dans la formation du système cartésien. Paris: Vrin, 1984.

GOUHIER, H. La pensée métaphysique de Descartes. 4. ed. Paris: Librairie Philosophique J. VRIN, 1999. 
GRIMALDI, N. LA MORALE: Descartes. Paris: Vrin, 1992.

GUENANCIA, P. Descartes. Tradução: Lucy Magalhães. Rio de Janeiro: Jorge Zahar Editor, 1991.

. Le corps peut-il être un sujet? In: Descartes et la question du sujet. Paris: Presses Universitaires de France, 1999.

Gallimard, 1998.

L'intelligence du sensible: essai sur le dualisme cartésien. França: Éditions

GUEROULT, Martial. Descartes según el orden de las razones. Venezuela: Editora Monte Ávila editores Latino americana, 2005.

. Descartes selon l'ordre des raisons, vol. 1. Paris: Aubier, 1968.

. Descartes selon l'ordre des raisons, vol. 2. Paris: Aubier, 1953.

. Histoire de l' histoire de la philosophie. 3 vol. Paris : Aubier, 1984-1988.

. Philosophie de l' histoire de la philosophie. Paris, Aubier Montaigne, 1979.

GUEROULT, Martial. Descartes según el orden de las rasones. Tradução:

Francisco Bravo. Introdução : Jorge Secada Koechlin, 2 vol. Venezuela: Editora Monte Ávila editores Latino americana, 2005.

KAMBOUCHNER, Denis. L' Homme des passions: Commentaires sur Descartes, 2 vol. Paris: Albbin Michel, 1995.

- Les méditations métaphysiques de Descartes; Introduction générale; Première méditation. Paris: PUF, 2005.

LANDIM, Raul Ferreira Filho. A referência ao dêitico "EU" na gênese do sistema cartesiano: A res cogitans ou o homem?. In: Analytica. Rio de Janeiro, v. 1, n. 2, p. 41-67, 1994.

Filosofia; 23).

Evidência e verdade no sistema cartesiano. São Paulo: Loyola, 1992 (Coleção

. Idealismo ou realismo na filosofia primeira de Descartes. In: Analytica. Rio de Janeiro, v. 2, n. 2, p. 129-159, 1997.

HAMELIN, Octave. El sistema de Descartes. Tradução de Amalia Haydée Raggio. Buenos Aires: Losada, 1949.

LAPORTE, J. Le rationalisme de Descartes. Paris: PUF, 1945.

LEVY, L. Eu sou, eu existo: isto é certo; mas por quanto tempo? In: Analytica. Rio de Janeiro, v. 2, n. 2, p. 161-185, 1997.

LOPARIC, Zeljko. Descartes heurístico (Coleção Trajetória; 5). Campinas, SP: UNICAMP, Instituto de Filosofia e Ciências Humanas, 1997.

MARION, J-L. Sur l' ontologie grise de Descartes. 2. ed. PARIS: Vrin, 1991.

MOYAL, J. D. (Ed.). René Descartes critical assessments, 4 vol. London/New York: Routledge, 1991.

ONG-VAN-KUNG K. (Org.). Descartes et la question du sujet. Paris: Presses Universitaires de France, 1999. 
ROCHA, Ethel Menezes. Animais, Homens e Sensações Segundo Descartes. In: KRITERION. Belo Horizonte, no 110, p. 350-364, dez./2004.

- O Conceito de Realidade Objetiva na Terceira Meditação de Descartes. In: Analytica. Rio de Janeiro, v. 2, n. 2, p. 203-218, 1997.

Princípio de Causalidade, Existência de Deus e Existência de Coisas Externas. In: Cadernos de história e filosofia da ciência, série 3, v. 10, n. 1, p. 7-30, jan./jun. 2000.

Prudência da Vontade e Erro em Descartes. In: Verdade, conhecimento e ação: ensaios em homenagem a Guido Antônio de Almeida e Raul Landim Filho. São Paulo: Edições Loyola, p. 325-337, 1999.

RODIS-LEWIS, Geneviéve. Descartes e o racionalismo. Tradução: Jorge de Oliveira Baptista. Porto: Rés Editora, 1979.

SCHIRMER, C. A afirmação da existência dos corpos nas Meditações de Descartes: verdade e propensões incorrigíveis. Porto Alegre. Dissertação de Mestrado - Programa de Pós-Graduação em Filosofia, UFRGS, 2003.

SCRIBANO, Emanuela. La nature du sujet. Le doute et la conscience. In: Descartes et la question du sujet. Paris: Presses Universitaires de France, p. 49-66, 1999.

SOARES, Alexandre Guimarães Tadeu de. O filósofo e o autor. Campinas: Editora Unicamp, 2008.

TALON-HUGON, Carole. Descartes ou les passions rêvées par la raison: essai sur la théorie des passions de Descartes et de quelques-uns de ses contemporains. Paris: Vrin, 2002.

TEIXEIRA, Lívio. Ensaio sobre a moral de Descartes. 2. ed. São Paulo: Brasiliense, 1990.

VALENTIM, Marco Antônio. Uma conversação premeditada: a essência da história na metafísica de Descartes. 2007. 193 f. Tese (Doutorado em Filosofia) - Programa de Pós-Graduação em Filosofia, Instituto de Filosofia e Ciência Sociais, UFRJ. 2007.

Endereço do Autor:

Travessa Salomão Lima da Silva, 417 - casa 3

Cond. Ypê, Bairro Centenário

69312-535 Boa Vista - RR

edgardzanette1@gmail.com 